\title{
WHAT WORDS MEAN IS A MATTER OF WHAT PEOPLE MEAN BY THEM*
}

\author{
Tim Wharton** \\ University of Brighton \\ Brighton, England
}

\begin{abstract}
This paper considers the extent to which lexical acquisition is an exercise of an associationist ability, a general mind-reading ability or a specifically pragmatic ability. Particular attention is paid to the role played in word-learning by natural communicative phenomena-gaze direction, facial expression, tone of voice etc.-and to the question of how such behaviours might be accommodated within a pragmatic theory. As well as sketching some possible directions in which future research into the pragmatics of lexical acquisition might proceed I will also suggest, given recent research in relevance theoretic lexical pragmatics, that there are interesting parallels to be drawn between the processes at work in lexical acquisition and those at work in adult comprehension.
\end{abstract}

Keywords: Associationism. Acquisition. Theory of Mind. Natural Pragmatics. Mindreading.

\section{INTRODUCTION 1}

This article has two aims. Firstly, I will sketch a framework within which we can explore how speakers provide clues to the intended meanings of their words to (a) young children acquiring the meanings of those words and (b) to adult (or child) interlocutors in communicative exchanges. The discussion involves, on the one hand, the human meta-psychological abilities so central to human communicationmindreading or Theory of Mind (BARON-COHEN, 1995) - and, on the other, what I have elsewhere called 'natural pragmatic' factors (WHARTON, 2003, 2009): the largely natural, non-verbal behaviours that inevitably accompany speech (e.g. tone of voice, facial expression) often known as 'paralinguistic' phenomena (see WHARTON (forthcoming)). Secondly, I want to suggest that there are interesting parallels to be drawn between the processes at work in lexical acquisition and in adult comprehension: the words that are the title of this chapter (purloined from Grice himself) are eerily prophetic.

In §2 I consider lexical acquisition in the light of two contrasting accounts: the first proposes that it is an exercise of an associationist ability; the second that a general

\footnotetext{
* Grice (1989, p. 340).

${ }^{* *}$ Senior Lecturer in Linguistics at University of Brighton, England. PhD in Linguistics, University College London, England. E-mail: t.wharton@brighton.ac.uk.

${ }^{1}$ This article is based on ideas first presented in a 2004 UCL Working Paper, which evolved from work supported by AHRB Research Grant MRG-AN9291/APN16356 'A unified theory of lexical pragmatics'. The ideas had lain dormant for some time and I thank the team at PUCRS for encouraging me to revisit them and write this updated version. I also thank Deirdre Wilson for comments on earlier drafts and, indeed, for her continued support.
} 
mindreading ability is involved. I present arguments in favour of the latter approach. Acquiring the meanings of words is largely a matter of working out, using (among other things) natural, non-verbal cues, what it is that people are referring to when they use them. In $\S 3$ I outline the theoretical framework adopted here, Relevance Theory (SPERBER; WILSON, 1986/1995, 2013), and show that since understanding utterances is as a matter of working out, using natural, non-verbal cues, the intentions behind them, the skills implicated in the way adult speakers use and understand them are the same skills that the second approach regards as crucial to the way children acquire the meanings of words. I then go on to consider the extent to which lexical acquisition might be an exercise of a pragmatic, as opposed to a general mindreading ability. In $\S 4$ I revisit earlier work of my own on the 'showing-meaning ${ }_{\mathrm{NN}}$ ' continuum (WILSON; WHARTON, 2006; WHARTON, 2009), which concerns itself with how natural, nonverbal behaviours might be accommodated within a pragmatic theory. In the final section, I tie up the loose ends and propose some of the experimental implications adopting this framework might have as well as pointing to the parallels mentioned above.

\section{LEXICAL ACQUISITION AND MINDREADING}

The remarkable precocity children exhibit in their ability to learn words is well documented. According to Paul Bloom (2000), from the age of 12 months children acquire roughly ten new words a day. By the time they are 17 they will have attained a vocabulary of (on a conservative estimate) 60,000 words. In the absence of formal training, very young children 'fast-map' words to meanings after only one or two exposures. Sometimes (in the case of many verbs, for example) not even the virtual absence of explicit naming by carers affects the child's ability to map new words onto actions.

Central to Bloom's thesis is the claim that the child's sensitivity to the mental states of others plays a hugely important role in the process of lexical acquisition. In his 2001 précis, Bloom (2001, p. 1094) elaborates:

\footnotetext{
This proposal is an alternative to the view that word learning is the result of simple associative learning mechanisms, and it rejects as well the notion that children possess constraints, either innate or learned, that are specifically earmarked for word learning.
}

The view that word learning is the result of associative learning mechanisms (BLOOM, L., 1994, p. 91) can be traced back to the Empiricist philosophers. Under this view, children form reliable associations between words and their meanings as a result of their sensitivity to statistical co-occurrences between what they see and what they hear. Bloom P.'s alternative view argues that rather than just being sensitive to statistical correlations, children are sensitive to the referential intentions of speakers. Under this view, acquiring the meanings of words is largely as a matter of working out, using natural, non-verbal cues, what it is that people intend to refer to when they use them. He provides a whole range of convincing arguments to support a mind-reading model over an associationist one. 
In the first place, the input the child receives is flawed in key regards. In some cultures, for example, parents and carers do not overtly name objects for children at all, yet word-learning proceeds at the same rate as in cultures where they do. Even in cultures where objects are overtly named by parents and carers, it is not always the case that a child will be looking at the object being named at the time they hear the word for that object. If word learning were simply a matter of associationist correlation, then on the basis of the input they receive we would expect the child to make many mapping errors in the course of word learning. The fast-mapping by children of words onto meanings is conspicuously error-free.

Secondly, there is experimental evidence to favour a mindreading model over an associationist one. In a series of experiments, Baldwin (1991, 1993) effectively tested the two models. A child was given an object to play with while another, different, object was put into a bucket in front of the experimenter. Whilst the child was looking at the object she was playing with, the experimenter looked at her object and said a novel word-'It's a modi'. As Bloom (2000, p. 64) reports:

\footnotetext{
This gives rise to a perfect Lockean correspondence between the new word and the object the baby was looking at. But 18-month-olds don't take modi as naming this object. Instead, they look at the experimenter and redirect their attention to what she is looking at... [T]hey assume that the word refers to the object the experimenter was looking at when she said the word - not the object that the child herself was looking at.
}

Thirdly and finally, a mindreading model predicts that autistic individuals, who have impaired mind-reading abilities (LESLIE, 1987; HAPPÉ, 1994, BARON-COHEN, 1995; SCHOLL; LESLIE, 1999) and have problems with pragmatic tasks generally, should show impaired word learning abilities. This is indeed the case. Baron-Cohen et al. 1997 replicated Baldwin's experiments with autistic children. As predicted by the mindreading model, these children assumed that the word modi referred to the object they, rather than the experimenter, were looking at. Autistic children do not monitor gaze direction (MUNDY et al, 1986) and the autistic child remains unaware that the experimenter is intending to refer to something other than the object the child herself is looking at.

If mindreading is so centrally implicated in the way children learn words, then natural pragmatic factors will play a crucial role. Facial expression, gesture and gaze direction all provide an audience with vital clues as to the mental states of the others. Gaze direction is clearly one of the most important factors at play and in Baldwin's experiments, it is the most crucial piece of evidence that the child has as to the experimenter's intentions. Indeed, gaze direction is such a reliable indicator of aspects of another's intentions that it seems plausible to suggest that humans have an evolved, dedicated mechanism to monitor it. Baron-Cohen (1995) proposes that there is an 'Eye Direction Detector', which might form a sub-module of the wider mind-reading module. Infants are disposed at a very early age to monitor eyes: Barrera and Maurer (1981) showed that two-month-old infants look significantly more at an adult's eyes than at other regions of their face; Papousek and Papousek (1979) suggest that six-month-old infants look up to three times longer at a face that is looking at them than at one that is looking away. 
Of course, at this very early stage in development, the child may just be 'tuningin' to gaze direction, rather than attributing complex mental states (such as intentions) on the basis of it. Nonetheless, it appears that gaze direction quickly comes to be perceived as the main way adults indicate objects to children in the naming process. At a similarly early age, children follow adults' pointing gestures. By the age of one the child herself begins pointing, and monitors the gaze direction of the adult to check whether she has been successful in changing the focus of their attention. As well as the problems autistic individuals have tracking gaze direction, Sigman and Kasari (1995) show how even basic acts of showing such as pointing are problematic for autistic individuals, predicting precisely the results found in Baron-Cohen et al. (1997).

At a later stage in her development, the child tracks not just gaze direction in word learning tasks, but also emotional expression as evidenced by facial expression and tone of voice. Tomasello and Akhtar (1994) report that children tracked not only the gaze but also the facial expression and tone of voice of experimenters while they searched for an object being named with a novel word ('toma'). When the experimenter had clearly found her goal, the child recognised this was so by interpreting her emotional expression, and understood the word accordingly. Interjections and other expressions of emotion also play a role. In Tomasello and Kruger (1992) an experimenter uttered an unfamiliar verb when telling the child what action she was about to perform. She then performed two actions, one accompanied by an expression such as 'whoops', which indicated the action was accidental, and the other accompanied by a word indicating the action was intended. The child monitored the experimenter's reactions and took the verb to refer to the intended action, rather than the apparently accidental one. Since autistic individuals also have problems interpreting emotional states (HOBSON; OUSTON; LEE, 1988; MURIS; MEESTERS; MERCKELBACH; LOMME, 1995) the prediction would be that they would fail in experiments such as these.

Bloom attributes the often somewhat bizarre use of words by autistic individuals to the fact that they only have associationist, rather than mind-reading strategies to resort to in lexical acquisition. Diesendruck (2004) suggests that those non-human animals that acquire limited vocabularies (such as trained bonobos) also do so by using associationist abilities. However, as Sperber (2004) notes in response to Diesendruck, it is not the case that autistic children have no interpretive abilities at all. An alternative possibility is that their interpretive abilities are limited by their failure to comprehend natural pragmatic cues such as gaze direction, tone of voice, facial expressions of emotion, etc., but that they are still performing recognisably pragmatic inferences in comprehension, and in particular in word learning. In the next section, I take up this proposal and consider the extent to which lexical acquisition might be an exercise of a pragmatic, as opposed to a general mind-reading ability.

\section{LEXICAL ACQUISITION AND RELEVANCE 3.1 RELEVANCE THEORY}

Relevance theory (SPERBER; WILSON, 1986/1995) takes its lead from Chomskyan and Fodorian insights into language and mind, and combines a broadly Gricean intention-based pragmatics with aspects of cognitive science and modern psychological research to provide a cognitive-inferential pragmatic framework. 
Relevance theory is built around two principles. The Cognitive Principle of Relevance makes a fundamental assumption about human cognition: the human cognitive system is geared to look out for relevant information, which will interact with existing mentally-represented information and bring about positive cognitive effects based on a combination of new and old information. Relevance itself is a property of inputs to cognitive processes, and is defined in terms of cognitive effects gained and processing effort expended: other things being equal, the more cognitive effects gained, and the less processing effort expended in gaining those effects, the greater the relevance of the input to the individual who processes it.

The human disposition to search for relevance is seen as an evolved consequence of the tendency toward greater efficiency in cognition (SPERBER; WILSON, 2002). It is, furthermore, a disposition that is routinely exploited in human communication. Since speakers know that listeners will pay attention only to stimuli that are relevant enough, in order to attract and hold an audience's attention, they should make their communicative stimuli appear at least relevant enough to be worth processing. More precisely, the Communicative Principle of Relevance claims that by overtly displaying an intention to inform-producing an utterance or other ostensive stimulus - a communicator creates a presumption that the stimulus is at least relevant enough to be worth processing, and moreover, the most relevant one compatible with her own abilities and preferences. This Communicative Principle motivates the following relevance-theoretic comprehension procedure-taken from Wilson and Sperber (2002, p. 13):

Relevance theoretic comprehension procedure

(a) Follow a path of least effort in computing cognitive effects: Test interpretive hypotheses (disambiguations, reference resolutions, implicatures, etc.) in order of accessibility

(b) Stop when your expectations of relevance are satisfied

In the simplest case, an interpreter using the relevance-theoretic comprehension procedure would follow a path of least effort in interpreting an utterance, and stop at the first interpretation that he found relevant enough. For more complex cases, see below.

The inferential processes required by this account are unconscious and fast, and the comprehension procedure can be seen as a 'fast and frugal heuristic' of the kind currently gaining much currency in cognitive science (GIGERENZER; TODD 1999; KAHNEMAN, 2011). In this respect, the relevance theoretic approach diverges from more traditional Gricean accounts of comprehension (see GRICE, 1989, p. 30-31) indeed, from philosophical characterisations generally - which rationally reconstruct the comprehension process in the form of conscious and reflective inferences about the mental states of others. This raises the question of the precise relationship between the mechanisms responsible for the latter kind of inferences, which (mature) individuals are certainly capable of, and those deployed in spontaneous comprehension.

Sperber and Wilson (2002) present arguments to suggest that there is more to the interpretive processes that underlie verbal comprehension than general mind-reading abilities of the type evoked by Grice. Their proposal is that the processes that underlie verbal comprehension might be performed by a domain-specific 'comprehension' 
mechanism or module (SPERBER, 1994b, 2000). ${ }^{2}$ The function of such a mechanism would be to interpret ostensive stimuli using the relevance-based comprehension procedure. They justify this conclusion on the following lines. Firstly, the types of 'meaning' that a speaker can convey by producing an utterance are generally much more complex than the types of intention normally attributed to someone in order to explain their observed behaviour. Specialised mechanisms for the interpretation of speakers' meanings appear therefore to be necessary. Secondly and relatedly, we often attribute intentions to others by observing the effects of their actions, deciding which of those effects they might have desired, and attributing to them the intention to achieve those desired effects: for example, observing someone climb a tree and pick an apricot, we may infer that his intention in climbing the tree was to pick an apricot. However, a speaker will achieve very few effects by producing an utterance unless she is first understood, so the normal procedures for recognising the intentions behind ordinary non-communicative actions won't work: the hearer can't first observe the effect of an utterance and then infer what it meant. Third, on broadly Gricean accounts of communication, in order to understand intentional communication, as opposed to ordinary non-communicative behaviour, it is necessary to be able to attribute several layers of metarepresentations; yet young children below the age of 4 - the same children who (as do autistic subjects) fail standard mind-reading tests-master verbal communication quickly and effortlessly well before this age. Moreover, they acquire words effortlessly too.

A fully developed mindreading ability, or 'first-order' theory of mind, is often equated with ability to pass a first-order version of the false-belief test (see BARONCOHEN, 1995; SCHOLL; LESLIE, 1999). In this test, a child and an experimenter watch while an object is placed in a certain location. The experimenter then leaves the room and the object is moved to a new location (now unknown to the experimenter). When the experimenter returns to the room, the child is asked where she will look for the object. If the child can attribute a belief to the experimenter about the location of the object which differs from the belief she herself holds (i.e. one that is false), she will say that the experimenter will look in the wrong place. This presents a problem for an account that claims that general mind-reading abilities are put to use in word learning (which is under way well before children can pass the false-belief task). Why, when they acquire words so successfully, do children fail the false-belief task?

One answer would be to suggest that the false-belief task is testing for something more complex than the ability to attribute mental states (see BLOOM; GERMAN 2000). There is a growing literature on the question of how it is that children can be adept interpreters of utterances before they can read minds (in the sense of pass regular false-belief tasks), and a variety of different camps are emerging. In the first camp, there are those (TOMASELLO; BARTON, 1994; AKHTAR; CARPENTER; TOMASELLO, 1996; HAPPÉ, LOTH, 2002) who warn against underestimating the inferential abilities of young children. In another there are those (RECANATI, 2002; BREHENY, 2006) who claim that we overestimate the degree to which the inferential attribution of intentions is a prerequisite to verbal communication. Research over the past ten years

\footnotetext{
${ }^{2}$ I use the term 'module' in the sense of Sperber (1994b) and, indeed, much of the literature on evolutionary psychology: that is, in a somewhat 'looser' sense than the one originally proposed by Fodor (1983).
} 
puts an interesting new slant on the debate. Onishi and Baillargeon (2005) suggest that on the basis of results from a new experimental paradigm, children as young as 15 months can pass a non-verbal variant of the false-belief task. Southgate, Chevallier and Csibra (2010) demonstrate that 17-month-old children appeal to false beliefs in order to understand the referential intentions of others.

Another solution would be to propose that word learning is facilitated by the same comprehension module that is responsible for intentional communication. This module is capable of generating complex, multi-layered metarepresentations specifically in communicative situations. Happé and Loth (2002) provide experimental evidence that supports this claim. They show that young children below the age of 4 , who regularly fail basic first order theory of mind tests, are able to track false beliefs if the task is adapted so that it becomes a word-learning task. Akhtar (2002) provides experimental evidence suggesting that expectations of relevance play a role in lexical acquisition, and in particular that children's hypotheses about word meaning seem to be produced by following a path of least effort, as described in the relevance-theoretic comprehension procedure. There is evidence from pathology too. Individuals with Asperger's Syndrome - an autism-related condition (FRITH, 1991) - show typically impaired mind-reading abilities, but 'normal' language acquisition. Again this suggests a degree of dissociation between the mind-reading skills underlying social interaction, which autistic individuals and people with Asperger's Syndrome find hugely problematic, and those underlying language acquisition.

In contrast to Bloom's proposal that autistic individuals bring simple associative mechanisms to bear on the word-learning process, the relevance-theoretic position suggested by Sperber (2004) is that they, just like normal children, are using the relevance-theoretic comprehension procedure and following a path of least effort, but on the basis of impoverished input caused by their inability to interpret 'natural pragmatic' clues such as gaze direction, pointing, facial expressions, etc. More generally, autistic individuals typically use the least sophisticated of three interpretive strategies proposed by Sperber (1994a). When they can find the right interpretation by following a path of least effort and accepting the first interpretation that they find relevant enough ('Naive Optimism'), comprehension will succeed. However, they will fail in cases requiring more sophisticated strategies: for example, where the speaker is mistaken about what they will find relevant enough ('Cautious Optimism'), or is engaged in some forms of deceit ('Sophisticated Understanding') (see SPERBER, 1994a; WILSON, 2000). By contrast, normal children become capable of Cautious Optimism (and hence of adjusting their interpretations to take account of the speaker's mistaken beliefs) at around the same time as they pass standard first-order belief tests.

\subsection{COMPREHENSION AND MINDREADING}

The basic proposal I want to make is this: since understanding utterances is as a matter of working out the intentions behind them, the skills implicated in the way adult speakers use and understand them are the same skills that Bloom sees as crucial to the way children acquire the meanings of words. Just as children are required to attribute intentions and interpret natural cues in order to acquire word meanings, so adult hearers 
must do so in order to interpret successfully the words they hear. Indeed, the way children acquire words may provide them with clues as to how they are used.

One similarity between relevance theory and Grice's pragmatic framework is that both distinguish (in different ways, and using different terminology) between the explicit and the implicit content of an utterance. The relevance-theoretic distinction between explicatures and implicatures bears some similarity to Grice's distinction between saying and implicating. However, the two pairs of notions are certainly not identical (see CARSTON, 2002). In Grice's framework, pragmatic inference contributes mainly to implicatures. In relevance theory, explicatures are recovered via a mixture of linguistic decoding and pragmatic inference, and are also a matter of degree: the greater the degree of linguistic encoding, the more explicit the explicitly communicated content of the utterance.

A second difference between Gricean pragmatics and relevance theory, and a central claim of relevance-theoretic pragmatics, is that explicatures and implicatures are developed in parallel, with the explicit content being adjusted or 'fine-tuned' in various ways in order to yield the implicatures required to satisfy the audience's expectations of relevance. In particular, encoded lexical meanings may have to be narrowed or loosened (assigned a narrower or broader denotation) in order to yield the expected level of implicatures (CARSTON, 1997, 2002; SPERBER; WILSON, 1998; WILSON, SPERBER 2002). Just as natural cues play a central role in lexical acquisition, so they also play a role in lexical pragmatics, the adjustment of encoded conceptual content. Crucial to lexical pragmatics is the observation that there is an interaction between decoding and inference not only the level of what is explicitly communicated by a whole sentence, but at word level too: a particular word may be used to express not exactly the concept it encodes, but a broader or narrower concept whose construction is constrained by pragmatic principles (CARSTON, 2010; WILSON; CARSTON, 2007).

In these cases, the hearer constructs an ad hoc concept guided by considerations of relevance (for more on the nature of ad hoc concepts, see ALLOTT; TEXTOR, 2012). This kind of adjustment of conceptual content is seen as one of the principal processes in explicit communication. Consider the word 'bear', the meaning of which might be narrowed in (1) to denote a sub-set of bears (e.g. polar bears), or loosened in (2) to include objects which are not strictly bears at all (e.g. large human beings):

(1) A bear walked out across the frozen sea.

(2) Chris was huge: he was a bear.

Indeed, the same cues that children use in the acquisition of words play a regular role in adult comprehension. Indeed, the interpretation of natural communicative phenomena feeds directly into the lexical adjustment process. Consider examples (3), (4) and (5) below:

(3) Jack: Shall we sit out here?

Lily (shivering ostensively): I'm cold.

(4) Lily (furiously): That makes me angry!

(5) Lily (smiling broadly): I feel happy. 
In (3), Lily and Jack meet outside a café. Lily's ostensive shiver accompanying her utterance of 'I'm cold' should be picked up by the relevance-theoretic comprehension procedure and used in interpreting the degree term 'cold'. The nature of the shiver will be treated as commensurate with the degree of coldness she feels, and, in effect, will calibrate the degree of coldness Jack understands her to feel and to be expressing as part of her meaning. The fact that Lily has shivered ostensively motivates Jack's search for the 'extra' meaning Lily intends to convey. Clearly in this case, implicatures may depend on it; thus, Jack might be entitled to infer that Lily is definitely cold enough to want to go inside. In a parallel example, Lily's ostensive shiver accompanying her utterance of 'It's lovely out here on the terrace, isn't it?' might provide Jack with a clue that she is being ironic, that actually she hates it on the terrace and that she would prefer to go inside. In both cases, shown natural behaviours feed into the interpretive process, guiding the hearer to a certain range or type of conclusions.

Notice, too, that the natural behaviours produced by Lily not only help Jack establish the implicit content of her utterance, but also contribute to the proposition he takes her to be expressing (or the basic-level explicature of her utterance). The truth conditions of her utterance of 'I'm cold' - and the truth-conditions of (4) and (5), which also contain degree terms - will vary according to the type or degree of 'coldness' (or 'anger' or 'happiness') she intends to communicate, and hence reflects in her natural behaviour (WHARTON, 2009; WILSON, CARSTON, 2007).

What Lily linguistically encodes by using the word 'angry', for example, is some quite general concept, which encompasses a considerable range of degrees and types of anger that may have to be narrowed during the comprehension process in order to satisfy Jack's expectations of relevance. The linguistically encoded content is calibrated by Lily's furious tone of voice and enriched by Jack to a concept-ANGRY*_-that he takes to be commensurate with the degree and type of anger Lily intends to convey. What she encodes by the use of the word 'happy' is also a quite general concept; again the occasion-specific sense is calibrated by reference to Lily's natural behaviours - in this example by features of her tone of voice and smile.

For autistic individuals, rather than providing important clues to the speaker's intended meaning, these subtle variations in pitch, and constantly shifting facial expressions, are nothing more than an irritating distraction. (See McCANN; PEPPÉ for a comprehensive review of interpretation of vocal cues by people with autism.) Consider the following, taken from the writings of Donna Williams, an author with autism:

\footnotetext{
Speak to me through my words,' I asked Dr. Marek. I wanted to cut down the struggle in putting mental pictures into words. 'Can you take the dancing out of your voice and not pull faces so you don't distract me from what you're saying (WILLIAMS, 1994, p. 95)
}

The 'natural' side of communication, then, remains totally alien, and this affects not only their regular interpretation of utterances such as (3)-(5) but also their lexical acquisition. (See McCANN; PEPPE, 2003 for an overview of the problems autistic people have interpreting prosody, and CHEVALLIER et al, 2010 for a slightly different view.) 


\section{NATURAL PRAGMATICS AND THE SHOWING-MEANING ${ }_{N N}$ CONTINUUM $^{-}$}

When I speak of 'natural' communicative phenomena, I have in mind phenomena that mean naturally (GRICE, 1957). In Grice's terms, 'means naturally' is roughly synonymous with 'naturally indicates', so in the same way that black clouds might be said to mean rain or smoke to mean fire, Lily's smile might be said to mean she is happy, or Jack's frown mean he is displeased. This can be contrasted with the kind of meaning inherent in language (often referred to as 'arbitrary' or 'conventional'), which Grice called non-natural; so the word pluie means 'rain'; Lily está feliz means 'Lily is happy', or "what that remark meant was 'Jack is displeased"”.

In Wharton (2009), I propose that behaviours which carry natural meaning in Grice's sense fall into two classes. The distinction is based on the ethological distinction between signals and signs made in Hauser (1996, p. 9-10). In the first class there are those natural behaviours that have a signalling function: ${ }^{3}$ the reason that these behaviours have propagated in our species is that they convey information to others about an individual's mental state (van HOOFF, 1972; FRIDLUND, 1994; EKMAN 1999). In the class of signals I include smiles and other facial expressions: 'These expressions have been selected and refined over the course of evolution for their role in social communication' (EKMAN, 1999, p. 51).

In the second class there are phenomena that carry natural meaning but do not have a signalling function: signs. In the class of signs I include, for example, shivering and bruises. Consider gaze direction as another example. The fact that someone's gaze is directed to a particular object lets others know what he is seeing; however, this is not its function but merely a by-product of the way the human visual system works. ${ }^{4}$

Although signs do not have a communicative function-in the sense that that is not the reason they have propagated in our species - they can be put to use in intentional communication. Indeed, all these natural behaviours, whether they are signs or signals, may be deliberately shown to an audience to provide evidence of an intention to inform.

Relevance theorists (SPERBER; WILSON, 1986/95, p. 53; WHARTON, 2009) have argued that there is a continuum of cases between (indirect) cases of Gricean meaning $_{\mathrm{NN}}$ and cases of 'showing', where the evidence provided for the first layer is relatively direct. This idea that there is a continuum of cases has implications for the domain of pragmatic principles or maxims, for it suggests that they are best seen as applying to the domain of intentional communication as a whole, rather than to the domain of meaning $\mathrm{N}_{\mathrm{NN}}$, as is generally assumed in Gricean accounts.

Among other things, the idea that there is a continuum of cases allows us to accommodate natural communicative behaviours within a pragmatic theory. The 'showing-meaning ${ }_{N N}$ ' continuum provides a snapshot of the types of evidence used in

\footnotetext{
${ }^{3}$ For discussion of various senses of the word 'function' see SPERBER (2007).

${ }^{4}$ As Hannes Rakoczy (p.c.) once suggested to me, there are other factors to bear in mind and-in the case of gaze direction - the situation is perhaps more complex than this. The upper part of the human face (and the human eye) has evolved in such a way that gaze direction is more easily identified (i.e. the 'whites' of a person's eyes enable another to infer where that person looking, the region around the eye has evolved in such a way as to make the eye itself clearly visible). Notwithstanding this, I still maintain it is not the function of the direction of gaze itself to signal where an individual is looking.
} 
intentional communicative acts. Such acts are typically a composite of inter-related behaviours falling at various points along the continuum. At one extreme of the continuum lie clear cases of spontaneous, natural display; at the other extreme lie clear cases of linguistic coding, where all the evidence provided for the first, basic layer of information is indirect. In between lie a range of cases in which more or less direct 'natural' evidence and more or less indirect coded evidence mix to various degrees (natural signals, for example). Gussenhoven and Chen (2000), Gussenhoven (2002) propose that the 'meaning' inherent in intonation may be either arbitrary or based on universal 'biological codes'. In the framework proposed here, intonation (indeed, prosodic elements generally) would occupy various positions along the continuum (see WILSON; WHARTON, 2006; WHARTON, 2009, forthcoming, for further discussion).

\section{CONCLUSION}

It seems clear that there is more to word learning than simple associationism, and that the attribution of mental states plays a crucial role in lexical acquisition. This paper has proposed, however, that just as there is more to human communication than general mind-reading abilities, so there is more to lexical acquisition than these abilities. Instead, lexical acquisition, in both normal and autistic children, is best viewed as an exercise of the relevance-theoretic comprehension procedure, governed by a dedicated module, which forms a sub-module of the wider mind-reading ability. Both normal and autistic children use this comprehension procedure, but autistic children have impoverished access to clues because of their independently well-attested inability to interpret gaze direction, pointing, emotional expressions, tone of voice, etc., as well as their general inability to think about what the speaker might have meant if their firstpass interpretation goes wrong. Chevallier et al. 2011 argue that a lack of social motivation may also be a factor.

As far as cognitive architecture goes, the picture that emerges is a complex one, in which rather than comprising one general mechanism, the human 'mind-reading' ability might be better characterised as involving a whole range of individual submodules, each interacting with natural coding-decoding mechanisms. Baron Cohen's (1995) proposal is that theory of mind is comprised of (at least) four mechanisms, each of which is subject to breakdown. In the case of autism, his hypothesis is that autistic individuals exhibit a deficit in the Shared Attention Mechanism, which in turn disrupts the development of the Theory of Mind Mechanism. This, it is claimed, is the mechanism underlying the ability to attribute complex epistemic mental states (or propositional attitudes) such as 'believe' and 'think': the mental states typically lacking in autistic individuals.

In Wharton 2009, I suggest that the fact that some natural cues are signals would predict that they too are interpreted by specialised, perhaps dedicated, neural machinery. This prediction appears to be borne out. Both non-human primates and humans have neural mechanisms dedicated to both recognising faces and processing facial expressions (GAZZANIGA; SMILEY, 1991). Baron-Cohen, Spitz and Cross (1993) examined the recognition of emotion in autistic children in more detail. Based on the observation that autistic individuals have problems in recognising beliefs, they speculated about the extent to which this would manifest itself in the recognition of 
'cognitive' emotions. These are emotions such as surprise, which, since they are caused by beliefs, presume some sort of understanding of beliefs. Baron-Cohen et al. regard these as distinct from 'simple' emotions-those emotions (such as happiness and sadness) caused by situations. As predicted, the autistic children had more difficulty recognising surprise (though see CHEVALLIER et al., 2011 for a different view). To the extent that these findings (and the suppositions on which they are based) are correct, it might be taken to suggest that while the meta-communicative and meta-psychological abilities in these subjects are impaired, certain of the mechanisms that decode signals remain intact. In current paradigms, lexical acquisition experiments do not recognise the sign-signal distinction, and potentially interesting questions are overlooked. Can the ability to interpret natural signals be impaired independently of other parts of the mindreading ability?

Lexical acquisition experiments also do not recognise the distinction between ostensive and non-ostensive use of natural cues. Notice that in these experiments gaze direction is not (or at least not always) used ostensively in the way it is in the example in $\S 4$. As we have seen, though, children are disposed from a very early age to monitor gaze direction (indeed, may have a sub-module dedicated to it), and since the fact that the adult is uttering words to the child is good evidence that he/she is communicating, the child's comprehension module (which presumably is not immune to false positives anyway) is activated. Happé and Loth (2002, p. 31) suggest that it would be interesting to monitor brain activity during observation of ostensive and non-ostensive acts in mental attribution tasks. It would also be informative to see whether the fact that a natural cue is used ostensively or non-ostensively would make any difference in a wordlearning task.

And finally, there seems to be a parallel worth exploring: given (a) that the gap that exists between the concept encoded by a word and the concept communicated by occasion-specific uses of that word; (b) that words are rarely used to convey their exact literal meaning; (c) that the way children acquire words might provide them with clues as to how they are used, and (d) that there are arguments to suggest that the specifically pragmatic 'comprehension' module may be implicated lexical acquisition as well as lexical pragmatics, it might at least be interesting to consider the extent to which understanding words (in normal adult comprehension) might be said to be a matter of acquiring new (in the sense of fine-grained, subtly nuanced and modulated by natural pragmatic factors) word meanings. After all, for children and adults alike, what words mean is a matter of what people mean by them.

\section{REFERENCES}

ABERCROMBIE, D. Paralanguage. British Journal of Disorders of Communication, London, The College Press, v. 3, 1996, p. 55-59.

AKHTAR, N. Relevance and Early Word Learning. Journal of Child Language, Cambridge, Cambridge University Press, v. 29, 2002, p. 677-686.

; CARPENTER, M; TOMASELLO, M. The Role of Discourse Novelty in Children's Early Word Learning. Child Development, Oxford, Blackwell, v. 67, 1996, p. 635-645.

ALlOTT, N; TEXTOR, M. Lexical Pragmatic Adjustment and the Nature of Ad Hoc Concepts. International Review of Pragmatics, Vancouver, v. 4, n. 3, 2012, p. 185-208. 
BALDWIN, D. Infant Contribution to the Achievement of Joint Reference. Child Development, Oxford, Blackwell, v. 62, 1991, p. 875-890.

Infants' Ability to Consult the Speaker for Clues for Word Reference. Journal of Child

Language, Cambridge, Cambridge University Press, v. 20, 1993, p. 395-418.

BARON-COHEN, S. Mindblindness: An Essay on Autism and Theory of Mind. Cambridge, MA: MIT Press, 1995.

; SPITZ, A.; CROSS, P. Do Children with Autism Recognise Surprise? A Research Note. Cognition and Emotion, London, Taylor and Francis, v. 76, 1993, p. 507-516.

; BALDWIN, D; CROWSON, M. Do children with Autism Use the Speaker's Direction of Gaze Strategy to Crack the Code of Language? Child Development, Oxford, Blackwell, v. 68, 1997, p. 48-57.

BARRERA, M; MAURER, D. The Perception of Facial Expressions by the Three-Month-Old. Child Development, Oxford, Blackwell, v. 52, 1981, p. 203-206.

BLOOM, P. How Children Learn the Meanings of Words. Boston, MA: MIT Press, 2001a.

Précis of 'How Children Learn the Meanings of Words'. Behavioral and Brain Sciences, Cambridge, Cambridge University Press, v. 24, 2001b, p. 1094-1103

; GERMAN, T. Two Reasons to Abandon the False Belief Task as a Test of Theory of Mind. Cognition, Amsterdam, Elsevier, v. 77, 2000, B25-B31.

BREHENY, R. Communication and Folk Psychology. Mind and Language, Oxford, Blackwell, v. 211, 2006, p. 74-107.

BURTON-ROBERTS, N. (ed.) Pragmatics. London: Palgrave, 2007.

CARSTON, R. Thoughts and utterances: The Pragmatics of Explicit Communication. Oxford: Blackwell, 2002.

Lexical Pragmatics, Ad Hoc Concepts and Metaphor: From a Relevance Theory

Perspective. Italian Journal of Linguistics, v. 22, n. 1, 2010, p. 153-180.

CARRUTHERS, P.; BOUCHERS J. (eds.) Language and thought: Interdisciplinary Themes. Cambridge: Cambridge University Press, 1998.

; CHAMBERLAIN, A. (eds.) Evolution and the Human Mind: Modularity, Language and Metacognition. New York: Cambridge University Press, 2000

CHEVALLIER, C; NOVECK, I; HAPPÉ, F; WILSON, D. What's in a Voice? Prosody as a Test Case for the Theory of Mind Account of Autism. Neuropsychologia, 2010, p. 507-517.

CHOMSKY, N. Language and Problems of Knowledge: The Managua lectures. Cambridge, MA: MIT Press, 1988.

DIESENDRUCK, G. Word-Learning without Theory of Mind: Possible, but Useless. Contribution to the Online Discussion on Coevolution of Language and Theory of Mind. 2004. Available on: www.interdisciplines.org.

EKMAN, P. EMOTIONAL and Conversational Nonverbal Signals. In: MESSING, L.; CAMPBELL, R. (eds.) Gesture, Speech and Sign. Oxford: Oxford University Press, 1999. p. 45-57.

FODOR, J. The Modularity of Mind. Cambridge, MA: MIT Press, 1983.

FRIDLUND, A. Human Facial Expression: An Evolutionary View. San Diego: Academic Press, 1994

FRITH, U. (ed.). Autism and Asperger Syndrome. Cambridge: Cambridge University Press, 1991.

GAZZANIGA, M; SMILEY, C. Hemispheric Mechanisms Controlling Voluntary and Spontaneous Facial Expressions. Journal of Cognitive Neuroscience, Cambridge, MA, MIT Press, v. 2, 1991, p. 239245.

GIGERENZER, G; TODD, P. Fast and Frugal Heuristics: The Adaptive Toolbox. In: ABC Research Group. Simple Heuristics that Make us Smart. Oxford: Oxford University Press, 1999.

University Press, 1999 ; ABC Research Group. Simple Heuristics that Make us Smart. Oxford: Oxford

GRICE, H. P. Meaning. Philosophical Review, v. 66, 1957, p. 377-388. 
Utterer's Meaning, Sentence Meaning and Word-Meaning. Foundations of Language, v. 4, 1968, p. $225-242$.

Utterer's Meaning and Intentions. Philosophical Review, v. 78, 1969, p. 147-177.

Studies in the Way of Words. Cambridge, MA: Harvard University Press, 1989.

GUSSENHOVEN, C. Intonation and Interpretation. Proceedings of the First International Conference on Speech Prosody, Aix-en-Provence, ProSig and Université de Provence Laboratoire Parole et Language. 2002, p. 47-57.

; CHEN, A. Universal and Language-Specific Effects in the Perception of Question Intonation. International Conference on the Processing of Spoken Language, Beijing, v. 6, n. 2, 2000, p. 1-4.

HAPPÉ, F. Autism: An Introduction to Psychological Theory. Cambridge MA: Harvard University Press, 1994

The Autobiographical Writings of Three Asperger Syndrome Adults: Problems of Interpretation and Implications for Theory. In: FRITH, U. (ed.) Autism and Asperger Syndrome. Cambridge: Cambridge University Press, 1992. p. 207-242

; LOTH, E. Theory of Mind and Tracking Speakers' Intentions. Mind and Language, Oxford, Blackwell, v. 117, 2002, p. 24-36.

HAUSER, M. The Evolution of Communication. Cambridge, MA: MIT Press, 1996

HINDE, R. (ed.) Non-Verbal Communication. Cambridge: Cambridge University Press, 1972

HIRSCHFELD, L.; GELMAN, S. (eds.) Mapping the Mind: Domain Specificity in Cognition and Culture. Cambridge: Cambridge University Press, 1994.

KAHNEMAN, D. Thinking, Fast and Slow. New York: Allen Lane, 2011.

KHALFA, J. (Ed.) What is Intelligence? Cambridge: Cambridge University Press, 1994.

LAURENCE, S.; MARGOLIS, E. (eds.) Creations of the Mind: Theories of Artifacts and their Representation. Oxford: Oxford University Press, in press.

LESLIE, A. Pretense and Representation: the Origins of 'Theory of Mind'. Psychological Review, Washington: American Psychological Association, v. 94, 198, p. 412-426.

. ToMM, ToBY and Agency: Core Architecture and Domain-Specificit”. In: HIRSCHFELD, L.; GELMAN, S. (eds.) Mapping the Mind: Domain Specificity in Cognition and Culture. Cambridge: Cambridge University Press, 1994. p. 119-148.

; HAPPÉ, F. Autism and Ostensive Communication: the Relevance of Metarepresentation. Development and Psychopathology, Cambridge: Cambridge University Press, v. 1, 1989, p. 205-212.

McCANN, J; PEPPÉ, S. Prosody in Autism Spectrum Disorders: a Critical Review. International Journal of Language and Communication Disorders, v. 38, n. 4, 2003, p. 325-350.

MESSING, L.; CAMPBELL, R. (eds.) Gesture, Speech and Sign. Oxford: Oxford University Press, 1999. p. $45-57$

MUNDY, P; SIGMAN, M; UNGERER, J; SHERMAN, T. Defining the Social Deficits in Autism: the Contribution of Nonverbal Communication Measures. Journal of Child Psychology and Psychiatry, Oxford, Blackwell, 1986, p. 657-669.

MOORE C.; Dunham P. (eds.) Joint Attention: its Origins and Role in Development. Hillsdale, NJ: Lawrence Erlbaum, 1995

MURIS, P; MEESTERS, C; MERCKELBACH, H; LOMME, M. Knowledge of Basic Emotions in Adolescent and Adult Individuals with Autism. Psychological Reports, Montana, Ammons Scientific, $v$. 761, 1995p. 52-54.

ONISHI, K; BAILLARGEON, R. Do 15 month-old infants understand false beliefs? Science, American Association for the Advancement of Science, v. 308, 2005, p. 255-258.

ORIGGI, G; SPERBER, D. Evolution, communication and the proper function of language. In: CARRUTHERS, P.; CHAMBERLAIN, A. (eds.) Evolution and the Human Mind: Modularity, Language and Meta-Cognition. New York: Cambridge University Press, 2000. p. 140-169 
OZONOFF, S; PENNINGTON, B; ROGERS, S. Are there Emotion Perception Deficits in Young Autistic Children? Journal of Child Psychology and Psychiatry and Allied Discipline, Oxford, Blackwell, v. 31, n. 3, 1990, p. 343-361.

PAPOUSEK, H; PAPOUSEK, M. Early Ontogeny of Human Social Interaction: its biological roots and social dimensions. In: von CRANACH M. (ed.) Human Ethology: Claims and Limits of a New Discipline. Cambridge: Cambridge University Press, 1979.

PETER, H; OUSTON, J; LEE, A. What's in a face? The Case of Autism. British Journal of Psychology, British Psychological Society, v. 79, n. 4, 1988, p. 441-453.

RECANATI, F. Does Linguistic Communication Rest on Inference? Mind and Language, Oxford, Blackwell, v. 117, 2002, p. 105-126.

SIGMAN, M; KASARI, C. Joint Attention Across Contexts in Normal and Autistic Children. In: MOORE C.; Dunham P. (eds.) Joint Attention: its Origins and Role in Development. Hillsdale, NJ: Lawrence Erlbaum, 1995.

SCHIFFER, S. Meaning. Oxford: Clarendon Press, 1972.

SCHOLL, B; LESLIE, A. Modularity, Development and 'Theory of Mind'. Mind and Language, Blackwell, Oxford, v. 14, 1999, p. 131-153.

SKINNER, B. F. Verbal Behavior. New York: Appleton-Century-Crofts, 1957

SPERBER, D. Understanding Verbal Understanding. In: KHALFA, J. (ed.) What is Intelligence? Cambridge: Cambridge University Press, 1994a. p. 179-198.

The Modularity of Thought and the Epidemiology of Representations. In: HIRSCHFELD, L.; GELMAN, S. (eds.) Mapping the Mind: Domain Specificity in Cognition and Culture. Cambridge: Cambridge University Press, 1994b. p. 39-67

Metarepresentations in an Evolutionary Perspective. In: (ed.) Metarepresentations: a Multidisciplinary Perspective. Oxford: Oxford University Press, $\overline{2000 . p}$. 117-137. 2000 (ed.) Metarepresentations: a Multidisciplinary Perspective. Oxford: Oxford University Press,

Reply to Diesendruck. Contribution to the Online Discussion on Coevolution of Language and Theory of Mind. 2004. Available on: www.interdisciplines.org.

Seedless Grapes: Nature and Culture. In: LAURENCE, S.; MARGOLIS, E. (eds.) Creations of the Mind: Theories of Artifacts and their Representation. Oxford: Oxford University Press, 2007.

; WILSON D. Relevance: Communication and Cognition. Oxford: Blackwell, 1986/1995.

; $\quad$. The Mapping Between the Mental and Public Lexicon. In: CARRUTHERS, P.; BOUCHERS J. (eds.) Language and Thought: Interdisciplinary Themes. Cambridge: Cambridge University Press, 1998. p. 184-200. $\overline{17,2002, \overline{\text { p. } 3-23}}$

Pragmatics, Modularity and Mind-Reading. Mind and Language, Oxford: Blackwell, v.

SURIAN, L; CALDI, S; SPERBER, D. Attribution of Beliefs by 13 Month Old Infants. Psychological Science, v. 18, July 2007, p. 580-586.

TOMASELLO, M; AKHTAR, N. Two-Year-Olds Use Pragmatic Cues to Differentiate Reference to Objects and Action. Cognitive Development, v. 10, 1995, p. 201-224. p. 201-224.

BARTON, M. Learning Words in Non-Ostensive Contexts. Cognitive Development, v. 10: 1994, van HOOFF, J. A. R. A. M. A Comparative Approach to the Phylogeny of Laughter and Smiling. In: HINDE, R. (ed.) Non-Verbal Communication. Cambridge: Cambridge University Press, 1972. p. 209238.

WHARTON, T. Interjections, Language and the 'Showing'/'Saying' Continuum. Pragmatics and Cognition, v. 11, n. 1, 2003a, p. 39-91. $\overline{447-477 .}$

Natural Pragmatics and Natural Codes. Mind and Language, Oxford, Blackwell, v. 18, 2003b, p. 
The Pragmatics of Non-Verbal Communication. Cambridge: Cambridge University Press, in press.

von CRANACH M. (ed.) Human Ethology: Claims and Limits of a New Discipline. Cambridge: Cambridge University Press, 1979.

WILLIAMS, D. Nobody Nowhere: the Remarkable Autobiography of an Autistic Girl. London: Jessica Kingsley, 1992

WILSON, D. Metarepresentation in Linguistic Communication. In: SPERBER D. (ed.)

Metarepresentations: a Multidisciplinary Perspective. Oxford: Oxford University Press, 2000. p. 411-448

; CARSTON, R. A Unitary Approach to Lexical Pragmatics: Relevance, Inference and Ad Hoc

Concepts. In: BURTON-ROBERTS, N. (ed.) Pragmatics. London: Palgrave, 2007. p. 230-259

; SPERBER, D. Truthfulness and Relevance. Mind, v. 111, 2002, p. 583-632.

; WHARTON, T. Relevance and prosody. Journal of Pragmatics, v. 38, 2006, p. 1559-1579.

Recebido em 30/04/14. Aprovado em 15/08/14.

Título: O que as palavras significam é uma questão do que as pessoas querem dizer com elas.

\title{
Autor: Tim Wharton
}

Resumo: Este artigo considera até que ponto a aquisição do léxico é um exercício de uma capacidade associacionista, de uma capacidade geral de leitura de mente ou de uma capacidade especificamente pragmática. Presta-se especial atenção ao papel que os fenômenos comunicativos naturais - direção do olhar, expressão facial, tom de voz, etc. desempenham na aprendizagem de palavras, e à questão de como esses comportamentos poderiam ser incluidos dentro de uma teoria pragmática. Além de esboçar algumas direções possíveis de investigações futuras sobre a pragmática de aquisição do léxico, eu sugerirei, em função das recentes investigações em pragmática lexical fundamentada na teoria da relevância, que há paralelismos interessantes a serem traçados entre os processos que estão ativos na aquisição do léxico e os que estão ativos na compreensão de adultos.

Palavras-chave: Associacionismo. Aquisição. Teoria da Mente. Pragmática Natural. Leitura de Mente.

Título: Lo que las palabras significan concierne a lo que las personas quieren decir con ellas.

\begin{abstract}
Autor: Tim Wharton
Resumen: Este artículo considera hasta qué punto la adquisición del léxico es un ejercicio de una capacidad asociacionista, una capacidad general de lectura de la mente o una capacidad especificamente pragmática. Se presta una atención especial al papel que juegan en el aprendizaje de palabras los fenómenos comunicativos naturales - dirección de la mirada, expresión facial, tono de voz, etc. - y a la pregunta de cómo esta conducta podría ser incluida dentro de una teoría pragmática. Además de esbozar algunas direcciones posibles de futuras investigaciones sobre la pragmática de la adquisición de léxico, también sugeriré, dadas las recientes investigaciones en la pragmática léxica desde la teoría de la relevancia, que hay interesantes paralelismos que trazar entre los procesos que están activos en la adquisición del léxico y los que están activos en la comprensión de los adultos.
\end{abstract}

Palabras-clave: Asociacionismo. Adquisición. Teoría de la Mente. Pragmática Natural. Lectura de la Mente. 